\section{EXAMINATION OF LONDON WATERS}

$\mathrm{T}$

HE latest report of the Director of Water Examination of the Metropolitan Water Board* re-emphasizes the close control which is necessary in a large water undertaking drawing its supplies mainly from polluted or potentially polluted rivers. For routine control of water quality, some 45,000 samples are examined each year, and in addition the Board carries out a wide range of chemical, biological and engineering research, both in the laboratory and in large-scale experimental plant. One of the chief objects of the bacteriological research is to reduce the period necessary for confirming the presence in water of Bacterium coli Type I, a test which is of great importance in deciding whether a water is bacteriologically safe; in the majority of cases the whole test can now be carried out in thirty hours. The possibility of making a further big reduction in this period--in devising, in fact, a bacteriological test comparable with a chemical determination-would seem to depend on the discovery of some technique quite different from the present method of incubating samples in selective media at a controlled temperature.

A detailed account is given of the measures taken by the Board to sterilize jute yarn, of which some ten tons are used every year as a packing material in the jointing of mains. Many types of bacteria, including some pathogenic organisms, grow rapidly on this yarn; for example, Salmonella paratyphi $B$ multiplied 40 -fold within two days on yarn immersed in water at $22^{\circ} \mathrm{C}$. Before being used, therefore, the yarm is sterilized; it is washed in chloride-free water and is then treated with a solution of phenyl mercuric borate, this compound being fixed on the yarn by immersing it in a 6 per cent solution of sodium chloride; after treatment, samples of the yarn are examined in the laboratory for sterility. As a result of adopting this method, the proportion of bacteriologically unsatisfactory samples of water from repaired mains has been reduced from about 32 per cent to 6 per cent.

Several interesting examples are given of the introduction of automatic recording and controlling equipment, as a result of which some stations at which water is pumped from wells and chlorinated are now operated without a plant atterdant being always present; data on the working of the plant are recorded by electrical connexion at a central station, and there are automatic devices to shut off the pumps if, for example, the concentration of chlorine in water passing into supply deviates by more than a chosen amount from a mean value. The report records considerable progress in the automatic control of chlorination, the quantity being regulated by the rate of flow of water, and by its chlorine demand. Another interesting advance has been the development of equipment to record the thermal stratification of a reservoir. When stratification breaks down, the water passing into supply may for a time be of poor quality, and it is necessary, therefore, to have immediate warning of the change so that remedial measures can be brought into operation at once.

* Metropolitan Water Board. Thirty-sixth Report on the Results of the Bacteriological, Chemical and Blological kxamination of the London Waters for the years 1953-1954. By Dr. N. Windle Taylor Pp. $74+3$ plates. (London: Staples Press, Ltd., 1956.) 158. 6d.
Some little time ago there was a report that drinking waters in some parts of Britain contained undesirably high concentrations of copper. It is interesting, therefore, to know that in the whole of the area served by the Metropolitan Water Board there were, in 1953, ten complaints, and in 1954 twenty-one complaints of discoloured water thought to be due to the presence of copper. When these cases were investigated the supply was always found to be from an underground source, the water being taken to the consumer's premises in a copper pipe. The concentration of copper in the water from the main supply was usually from 0.1 to 0.2 part per million. It has been shown that with hard water similar to that in the London district, corrosion of copper-which is associated with the presence of films of carbon or copper oxide formed on the metal during manufacture-is limited or prevented by the presence of small quantities of an inhibitory substance which is present in surface waters but not in well waters.

Fxperiments with large-scale plant have been made on the treatment of water with coagulants. The results indicate that there is a strong case for adopting the use of activated silica in addition to aluminium sulphate; use of the silica has not made any marked improvement in the removal of algae, but it does give a denser and more rapidly formed floc and so improves the subsequent process of filtration. A process has been worked out for reclaiming coagulant from sludge, which is air-dried, roasted and extracted with sulphuric acid to yield a solution of aluminium sulphate which can be re-used.

B. A. Southgate

\section{REGIONAL ADVISORY COUNCILS FOR TECHNICAL AND FURTHER EDUCATION IN BRITAIN}

$T$

$\mathrm{HE}$ origin and main purposes of regional advisory councils for technical or further education were described in the White Paper on "Technical Education" presented to Parliament by the Minister of Education in 1956.

In England nine councils were voluntarily established by their constituent local education authorities and are financed by them in proportion to their populations. This is in contrast to the position in Scotland, where five regional advisory councils for technical education-based on Aberdeen, Dundee, Edinburgh, Glasgow and Inverness, respectivelywere statutorily established in April 1948 and financed from the Exchequer.

Most regional councils advise on all forms of further education, but in London the council is concerned with technology, commerce and industrial design and, primarily, with advanced work.

Much of the most valuable work of regional advisory councils is done on industrial advisory committees on which representatives of regional bodies of employers and operatives in a very wide variety of industries meet educational representatives to plan developments from the point of view of the region as a whole.

The nine English councils and their academic boards are constituted to a common pattern, with representatives on the council from constituent local 
education authorities, universities and university colleges, technical institutions and industry. The academic boards have stronger representation of universities and technical institutions. The Ministry of Education appoints assessors to all the councils and boards, and provision is often made for other Ministries to be represented.

Details of the constitution and functions of regional advisory councils have been set out in a pamphlet* together with a list of local authority areas included in each region. Copies can be obtained from the London Regional Advisory Council, Tavistock House South, Tavistock Square, London, W.C.1.

\section{T. H. HAWBINS}

* Constitution and Functions of Regional Advisory Councils and Local Authority Areas included in each Region. Pp. 12. (London : Regional Adv.
1956.) 28 .

\section{INSTRUMENTATION IN SCIENCE}

$T N$ recognition of the important part played by instruments in modern science, technology and business organization, the issue of Science of October 25,1956 , is largely devoted to instruments. There are eleven main articles, ranging from data processing for scientists and electronics for measuring human motions, to cryogenic instrumentation and phase microscopy. K. F. Heumann in his article on data processing maintains that scientists will require more assistance from machines in the matter of handling scientific data, and that techniques which have had recent, rapid development in business and accounting applications will prove most useful. $\mathrm{He}$ considers two such techniques-integrated data processing (IDP) and electronic data processing (EDP)-and refers to the 'Flexowriter', an electric typewriter equipped with a tepe punch and reader; the IBM type 705 EDPM machine, a large-scale generalpurpose data processor; and the UNIVAC FileComputer, a medium-size general purpose computer. In an article on cryogenic instrumentation, J. G. Daunt surveys recent progress in low-temperature technology, in particular, large-scale hydrogen and helium liquefaction plants; the separation of hydrogen isotopes by distillation; liquid hydrogen cooled electromagnets; bubble chambers; the magnetic refrigerator; and the thermal rectifier for use below $1^{\circ} \mathrm{K}$. In the field of high-temperature research, solar energy is superior to any other form of energy presently available, and T. S. Laszlo's article describing the various forms and advantages of solar furnaces is most valuable, though only a few such furnaces have so far been constructed. "FixedField Alternating Gradient Accelerators", by L. J. Laslett, deals in some detail with the recent new developments in the high-energy particle accelerator art which are mainly the results of study by members of the Mid-Western Universities Research Association.

An important new branch of technology encompassing the analysis, testing and processing of materials and products by the use of mechanical vibrating energy was named 'sonics' by R. H. Bolt and T. F. Hueter about two years ago, and in his article, "Sonic Techniques in Industry", T. F. Hueter gives a most instructive and illuminating survey of the basic physics involved and of the many fields of application ranging from oil-well drilling to medical therapy and molecular analysis. Other articles deal with a new principle of closed-system centrifugation developed at the Harvard Medical School, Boston, and chiefly applied in the blood field, though it has equal application to virus purification, milk stabilization, and the separation of other multiphase systems; low-level counting methods for isotopic tracers; the design study of a megacurie source; the 'Bendix' time-of-flight mass spectrometer; a device for measuring the performance of people at various work activities using the Doppler effect with sound, called a Universal Operator Performance Analyser (UNOPAR), and operating at $20 \mathrm{kc}$. $/ \mathrm{s.}$., which is just above the human threshold of hearing at normal levels of intensity; and finally, a review, including an extensive bibliography of 178 items, of published work on phase microscopy during 1954-56.

\section{AGRICULTURAL METEOROLOGY IN GERMANY}

7 WO interesting publications on agricultural meteorology have recently been issued by the Weather Service of the German Federal Republic.

The first of them, "Vorträge über Frostschutz" (Mitteilungen des Deutschen Wetterdienstes, 3, No. 16; 1956), reports the first meeting of the Association for Protection against Frost, held in Bonn on November 22, 1955, and the Symposium of the Technical Experiences of the German Weather Service in Protection against Frost, held on April 26, 1956, at Mainz. The task of the Association, which was set up by the Ministry of Food, Agriculture and Forests, is to further collaboration between agriculturists and meteorologists in this important subject. The pamphlet contains a list of the meteorological offices and of the centres for research in agricultural meteorology and provision of advice on agricultural meteorological matters, from which it is noteworthy that of the twenty meteorological offices in West Germany, eight are devoted to agricultural matters and three of the others are also agricultural offices. At Stuttgart there are two meteorological offices, one of which is an agricultural office.

The meetings of the Association discussed the education of farmers in frost protection by talks by agricultural meteorologists and the issue of posters drawn up by the Weather Service, giving of advice to local councils on planning to minimize frost damage and the establishment by them of a frost protection officer, and research into frost protection methods and the effects of frost on different plants. The organization for giving warning of the onset of frost by broadcasts and special telegrams is described in detail. Papers read at the symposium described methods of shielding orchards and vineyards from cold katabatic winds by judicious planting of trees and building of walls, and gave a good deal of information on methods of protection by spraying water, heating by oil burners, preventing the formation of a stagnant cold layer near the ground by stirring it up with propellors and sereening from radiation by smoke. Excellent diagrams of all these methods are given; those on the diversion of katabatic winds by shelter belts are particularly striking.

The second paper (Berichte des Deutschen Wetter. dienstes, 5 , No. 28 ; 1956) describes investigations by A. Baumgartner into the heat and water balance of a young pine forest near Munich. The author made measurements of radiation flux, temperature, 